\title{
An in vitro study to assess bioaccessibility and bioavailability of calcium from blue whiting (Micromesistius poutassou) fish bone powder
}

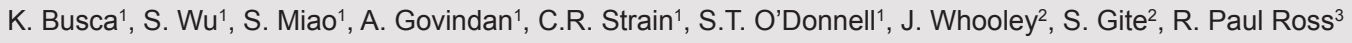 \\ and C. Stanton ${ }^{1 \dagger}$
}

${ }^{1}$ Teagasc, Food Research Centre, Moorepark, Fermoy, County Cork, Ireland

${ }^{2}$ Biomarine Ingredients Ireland Ltd., Killybegs, Co. Donegal, Ireland

${ }^{3} \mathrm{APC}$ Microbiome Ireland, University College Cork, Cork, Ireland

Abstract

The aim of this study was to determine how well calcium-rich mineral extracts derived from blue whiting fish bone powders compare with existing calcium sources (commercially available fish bone supplement, calcium carbonate and milk powder) in terms of physicochemical properties, in vitro bioaccessibility and bioavailability using simulated gastrointestinal tract treatment and a Caco-2 cell culture model. Blue whiting calcium-rich fish bone powders (A to E) were supplied by Bio-marine Ingredients Ireland (BII) and a commercial calcium-rich fish bone powder was used as the positive control $F$. The Bll calcium-rich fish bone powders analysed through atomic emission spectrometry were shown to have similar levels of mineral content in comparison with powder $F$. Solubility and rheology tests were performed on the rehydrated powders. The $\mathrm{pH}$ of Bll calcium-rich fish bone powders in water solution $(10 \%$ $w / v)$ ranged from 6.96 to 9.09 compared to control $F(p H ~ 7.33)$. Following simulated oral, gastric and duodenal in vitro digestion using the COST INFOGEST standardised static adult digestion method, the fish powders $A, E$ and $F$ showed higher values of soluble ionic calcium than rehydrated milk powder. We compared in vitro bioavailability of the powders using the Caco-2 cell line to test the effects of calcium on human colonic epithelial cells, which confirmed that calcium from blue whiting fish bone was more bioavailable than calcium from milk and calcium carbonate. These data indicate that calcium-rich blue whiting fish bone powder compares well with existing calcium sources, in terms of physicochemical properties, bioaccessibility and bioavailability.

Keywords

Calcium source $\cdot$ fish bone $\bullet$ in vitro bioaccessibility and bioavailability

\section{Introduction}

In the current global scenario, large amounts of agri-food waste and by-products are generated. The Food and Agriculture Organization (FAO, 2020) has estimated that globally onethird of all food produced is either wasted or lost, among which fruit, vegetables and the seafood sector constitute a major share. The fishing industry is a key contributor to the economy of numerous regions globally with annual production of over 178.5 million tonnes in 2018 as fish or shellfish from fisheries and aquaculture (FAO, 2020). Food waste disposal and byproduct management are issues of concern for aquatic and terrestrial environments along with the economic and food security implications (Ghosh et al., 2016; Torres-León et al., 2018).

The increase in annual fish production also generates large amounts of fish-processing by-products, which can account for up to three-quarters of the total fish weight (Rustad et al., 2011; Karayannakidis \& Zotos, 2016). Most of those fish-processing by-products are usually dumped in landfills or into the oceans having potentially harmful environmental effects or end up as low commercial value products - such as fish meal, fish silage and fertiliser (Rustad et al., 2011; Karayannakidis \& Zotos, 2016). Despite this, seafoods are inherently functional and possess many components that are beneficial for human health. These by-products contain valuable protein and lipid fractions as well as a variety of bioactive compounds with potential health benefits (Shahidi et al., 2019; Nguyen et al., 2020). In recent years, research is focused on utilising the ingredients originating from byproducts of the seafood industry in diverse sectors such as food, nutraceutical/functional food, pharmaceutical/ biomedical and fine chemicals (Shahidi et al., 2019; Nguyen et al., 2020). 
Fish and fish products have a central position in the functional foods arena as sources of calcium from fish bones and shells, anti-hypertensive proteins/peptides, antioxidants, selenium, chitin, omega-3 polyunsaturated fatty acids (PUFAs), taurine and other bioactive components (Ben-Othman et al., 2020). Fishing industry by-products such as fish bones and shells can be used as sources of value-added minerals such as calcium phosphates (Terzioglu et al., 2018). Extensive supplies of fish bones and crab shells exist in Ireland, most of which are classified as waste. Apart from their culinary value, these marine bivalves are regarded as a potential source of proteins, lipids, fatty acids ( $\omega-3$ PUFAs) and carbohydrates, which may have beneficial effects on human health (Gosling et al., 2008; Fernández et al., 2015).

Furthermore, previous studies reported that fishbone-derived peptides from hoki (Johnius belengerii (Cuvier, 1830)) and Pacific cod (Gadus macrocephalus (Tilesius, 1810)) also possess high calcium-binding activity which can improve calcium bioavailability and serve as a potential pharmacological substance for controlling bone metabolism, calcium absorption and anti-osteoporosis activities (Jung \& Kim, 2007; Peng et al., 2017; Heo et al., 2018; Zhang et al., 2018). Therefore, reutilisation of fish by-products in human nutrition could render positive health benefits and can also decrease disposal costs and risk of environmental pollution. Hence, the exploitation of aquaculture by-products for the extraction and investigation of high-quality proteins, lipids and carbohydrates might be of economic value. As there are potential health benefits reported for fish by-products, they might find an application as promising functional food ingredients in the future.

Calcium together with vitamin D play a crucial role in bone health for achieving and maintaining optimal bone mass (Ross et al., 2011; Flammini et al., 2016). Many dietary sources of calcium exist, although they may present problems with assimilation of the mineral. For example, dairy products are high in calcium, but many people are lactose intolerant, particularly those of Asian descent and people can also be allergic to dairy products. However, there is increasing public awareness of the importance of calcium in the diet and this has created a demand for dedicated calcium supplements. Many endogenous (parathyroid hormone $[\mathrm{PTH}]$, calcitonin and vitamin $\mathrm{D}_{3}$ ) and exogenous (food ingredients and specific diets) factors affect the bioavailability of calcium (Wawrzyniak \& Suliburska, 2021). Some food ingredients and dietary modifications can increase bone density and prevent osteoporosis by maintaining adequate calcium levels through endogenous pathways, thus it is important to include appropriate supplements that increase the bioavailability of calcium (Wawrzyniak \& Suliburska, 2021).

Calcium from fish bones may be highly bioavailable to humans, thus fish bone could be useful as a high-quality food ingredient or supplement that can help avoid calcium deficiency and reduce the risk of osteoporosis (Flammini et al., 2016; Zhang et al., 2018). A recent study found that calcified skeletal remains of the red marine algae species Lithothamnion (Heydrich, 1897), found off the coast of Ireland and Iceland, is a rich source of calcium and is available commercially as Aquamin in a number of forms, which have calcium concentrations ranging up to 31 weight percent (wt\%) (Brennan et al., 2017).

The fish bone powder used in this study is produced from low-value but highly sustainable whole fish biomass called blue whiting (Micromesistius poutassou (A. Risso, 1827)). Most of the fish bone powders available on the market are emulsified, not produced from whole fish but from fish off cuts or scales, skin and bones. However, the blue whiting fish bone powder used in this study is produced from whole fish which are non-emulsified, neutral in taste and odour through enzymatic hydrolysis, and hence has a huge potential as a functional food ingredient (Geirsdottir et al., 2011). In addition, the important seafood potential-recovered ingredients from blue whiting fish bone powder have $25 \%$ protein which is rich in collagen and is suitable for use in food, cosmetics and the pharmaceutical industries. This feature distinguishes it from existing calcium-rich supplements such as hydroxyapatite and calcium carbonate $\left(\mathrm{CaCO}_{3}\right)$ which have no protein content. This study investigated the bone fraction of blue whiting as a potential source of calcium given that bone fractions are currently considered as by-products of enzymatic hydrolysis with limited value. The fish bone samples used in this study were sourced from an Irish marine ingredients manufacturer (Bio-marine Ingredients Ireland, Co. Monaghan, Ireland), where five different bone powders $A, B, C, D$ and $E$ were produced from whole blue whiting fish and were compared and screened for their physicochemical properties and bioaccessibility of ionic calcium. The present study is first of its kind where the bioaccessibility and bioavailability of calcium from blue whiting bone powder was investigated.

\section{Materials and methods}

\section{Materials}

Five fish bone powders derived from blue whiting were provided by Bio-marine Ingredients Ltd (BII, Ireland). Original (A) blue whiting powder is a free-flowing, enzymatically hydrolysed powder with high calcium content and is fat free. The powder is white in colour and is an excellent source of calcium, phosphorous and other minerals (http://www. biomarine.ie/our-products/fish-bone-powder.221.html, BIl, Ireland). After developing a further optimisation process of milled twice and dried from the Original B-1 (A) powder, the other powders B-2 (B), C-60 (C), C-33 (D) and C-25 (E) were made. This material was clean, with no residual organic 
material having undergone enzymatic treatment. The BII fish bone powder $A$ was crude, while powders $B, C, D$ and $E$ underwent processing, with powder $E$ being most processed. $A$ commercially available bone fish powder F (NutriZing Calcium Fishbone, https://nutrizing.co.nz/product/calcium-fish-bonepowder/) was used as control for comparative purposes. The process of blue whiting bone powder production is robust where approximately $500 \mathrm{~kg} /$ day bone powder is produced industrially. Each experiment was performed using replicate samples of each powder (A, B, C, D, E and F) from their individual bulk sample obtained from BII.

\section{Compositional analysis of minerals}

Powders A (less optimised powder) and E (the most optimised powder) are selected to find differences between the optimisation process taking the most different powders $A$ and $E$ with the positive control $F$. The samples were analysed for mineral content and the data compared with the positive control (F). Samples were sent to an external company (Testing Laboratory No. 1163, Accredited by Czech Accreditation Institute [CAI] according to CSN EN ISO/IEC 17025:2005) for the following mineral analysis: calcium, phosphorous, magnesium, sulphur, potassium, sodium, zinc, manganese, iron, selenium, copper, boron and chloride. Samples of powders $A$ and $E$ were homogenised and mineralised by acids and hydrogen peroxide prior to analysis. Determination of elements was done by atomic emission spectrometry with inductively coupled plasma and stoichiometric calculations of compound concentration from measured values.

\section{Physicochemical properties of fish powders}

Particle size

Particle size of the powders (A, B, C, D, E and F) was determined using the Mastersizer 3,000 (Malvern Instruments Ltd, Worcestershire, UK). Measurements were conducted in duplicate samples and data were presented as mean \pm standard deviation.

\section{Microstructure}

Scanning electron microscopy (Carl Zeiss SMT Ltd., Cambridge, UK) was utilised for observing the surface and microstructure of powder samples, performing magnification $200 \times$ and 10,000x under $2 \mathrm{kV}$. Representative pictures of powders are provided in Figure 1

\section{Solubility}

The solubility of the powders ( $A, B, C, D, E$ and $F$ ) was assessed at room temperature $\left(20^{\circ} \mathrm{C}\right)$ and $50^{\circ} \mathrm{C}$ with one sample tested for each powder. The $\mathrm{pH}$ value was considered for rehydration of the fish powders, and for this $0.5 \mathrm{~g}$ powder was added to $25 \mathrm{~mL}$ buffer $\left(0.1 \mathrm{M}\right.$ citric acid/ $\left.0.2 \mathrm{M} \mathrm{Na}_{2} \mathrm{HPO}_{4}\right)$ at $\mathrm{pH} 3,4,5,6$ and 7, while water was used as control. The $\mathrm{pH}$ of buffers was determined by a $\mathrm{pH}$ meter (S220 Seven Compact, Mettler Toledo). Then, the solution of fish powder was stirred at $450 \mathrm{rpm}$ by a magnetic stirrer for $10 \mathrm{~min}$. The samples were centrifuged at $600 \mathrm{~g}$ for $10 \mathrm{~min}$. The supernatant was stored at $4^{\circ} \mathrm{C}$ for further experiments and the pellet was used to calculate the solubility of the powders. The pellet was incubated at different temperatures (room temperature and $50^{\circ} \mathrm{C}$ ) and the $\%$ of solubility was calculated as follows: [weight of powder (wp-sediment weight (sw)]/weight of powder (wp] * 100. The supernatant generated above was used to measure the soluble calcium ion and conductivity using a $\mathrm{pH} / \mathrm{ION}$ Meter kit (Mettler Toledo Ltd., Switzerland). The experiment was conducted with duplicate samples of each powder (A, B, C, $D, E$ and F).

\section{Determination of in vitro bioaccessibility using simulated gastrointestinal tract digestion}

To mimic the human gastrointestinal digestion conditions, a simulated in vitro static digestion was used based on a COST INFOGEST standardised method with some modifications (http://www.costinfogest.eu/) (Minekus et al., 2014; Egger et al., 2016). In order to determine the influence of optimisation process in the bioaccessibility, powder samples $A$ and $E$ were selected based on the difference in optimisation. The comparison was made with commercially available bone fish powder (sample $\mathrm{F}$ ), $\mathrm{CaCO}_{3}$ and milk powder as controls. The powders ( $A, E$ and $F$ ) were subjected to simulated oral, gastric and intestinal in vitro digestion processes, which was performed in duplicate.

The initial oral phase involved mixing of $10 \mathrm{~g}$ samples (powders $\mathrm{A}, \mathrm{E}, \mathrm{F}$ and $\mathrm{CaCO}_{3}$ ) with salivary simulant fluid (SSF) electrolyte stock solution. Then salivary $\alpha$-amylase solution $(1,500 \mathrm{U} / \mathrm{mL}), 0.3 \mathrm{M} \mathrm{CaCl}_{2}$ and water were added and each sample was mixed by incubating at $37^{\circ} \mathrm{C}$ for $2 \mathrm{~min}$ in a shaking water bath at $220 \mathrm{rpm}$. Briefly, each 20-mL sample mixtures from the oral phase was treated with simulated gastric fluid (SGF), $0.3 \mathrm{M} \mathrm{CaCl}_{2}$, porcine pepsin stock solution $(25,000 \mathrm{U} / \mathrm{mL}), 1 \mathrm{M} \mathrm{HCl}$ and water. The gastric $\mathrm{pH}$ was adjusted at 3.0. The gastric digestion phase was performed on each sample for $2 \mathrm{~h}$. After gastric digestion, $40 \mathrm{~mL}$ digestate of each sample was mixed with simulated intestinal fluid (SIF) containing pancreatin solution (800 U/mL), $10 \mathrm{mM}$ fresh bile, $0.3 \mathrm{M} \mathrm{CaCl}_{2}, 1 \mathrm{M} \mathrm{NaOH}$ to reach $\mathrm{pH}$ 7.0. All treatments were performed in duplicate by incubating for $2 \mathrm{~h}$ at $37^{\circ} \mathrm{C}$ in the shaker at $220 \mathrm{rpm}$. After simulated digestion and enzymatic inactivation $\left(100^{\circ} \mathrm{C}\right.$ for $10 \mathrm{~min})$, samples were centrifuged $\left(3,500 \mathrm{~g}\right.$ for $1 \mathrm{~h}$ at $\left.4^{\circ} \mathrm{C}\right)$ and the resultant supernatant was used for measurement of the final soluble calcium concentration using the $\mathrm{pH} / \mathrm{ION}$ Meter kit (Mettler Toledo Ltd., Switzerland). 
a $\mathbf{A}$
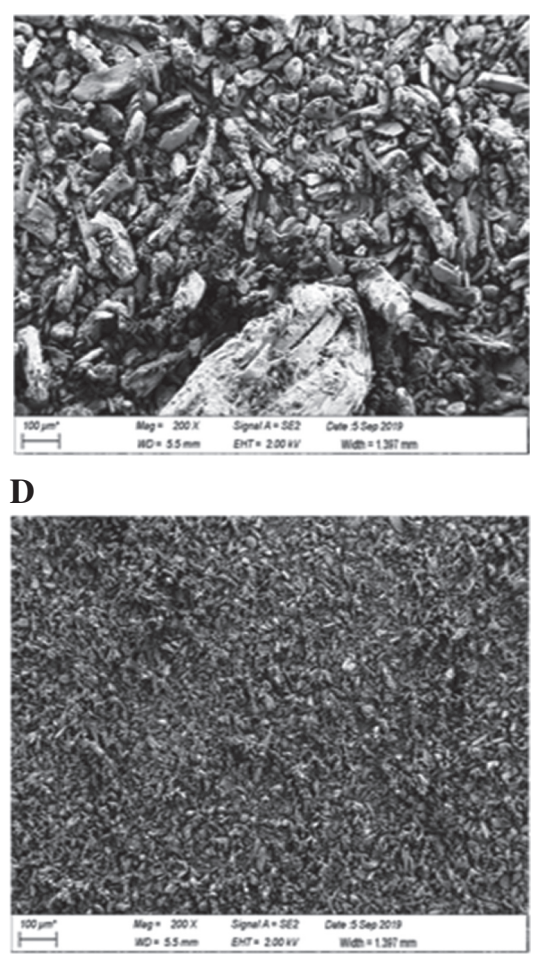

b A

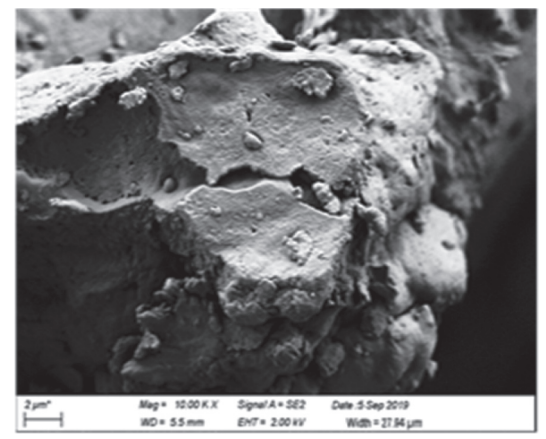

D

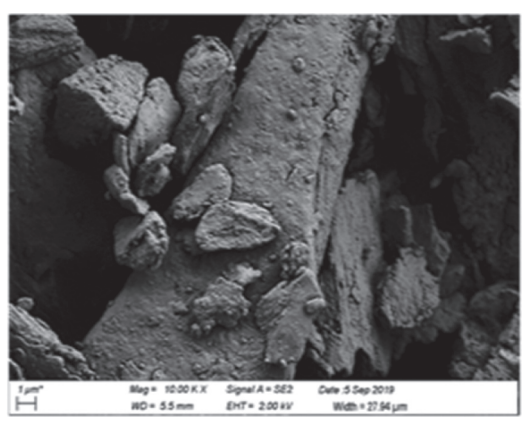

B

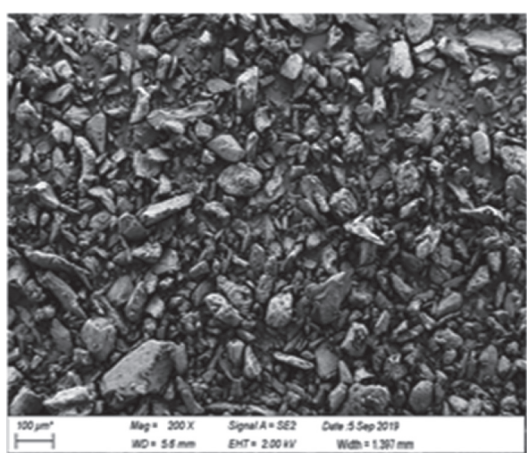

$\mathbf{E}$

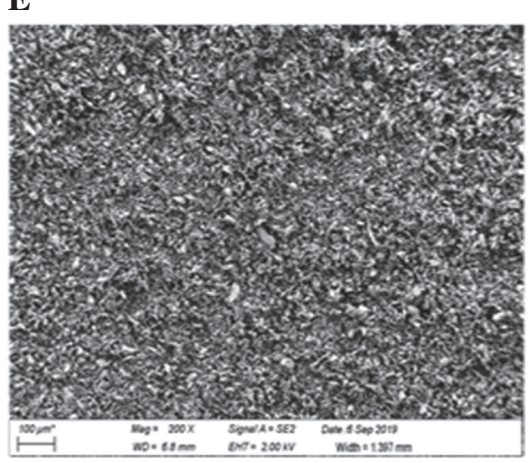

B

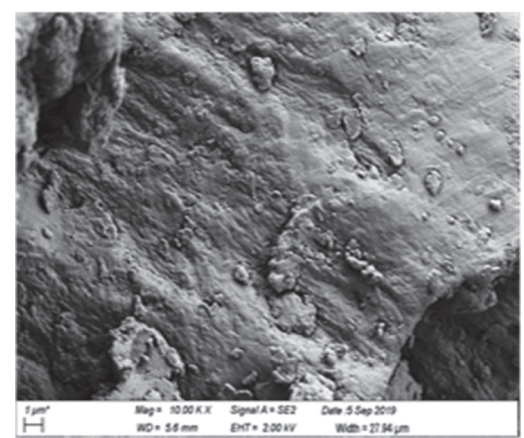

$\mathbf{E}$

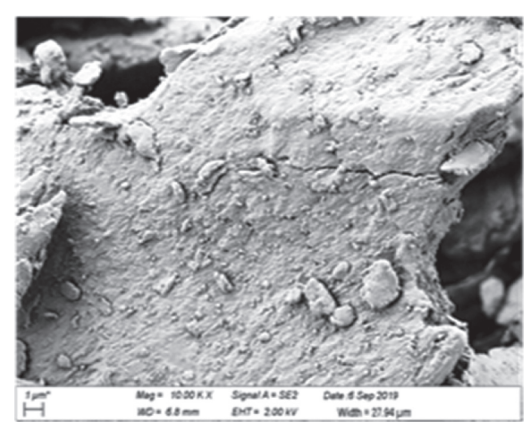

C

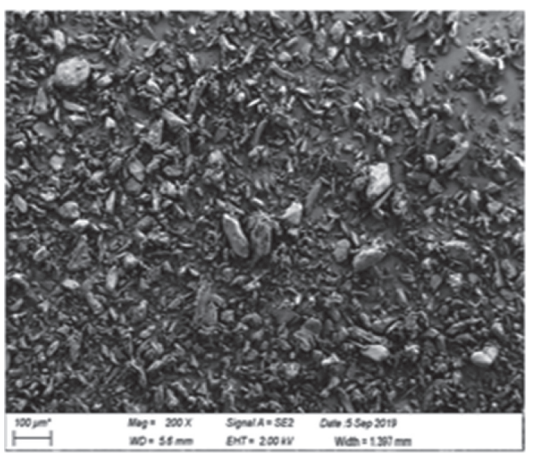

F

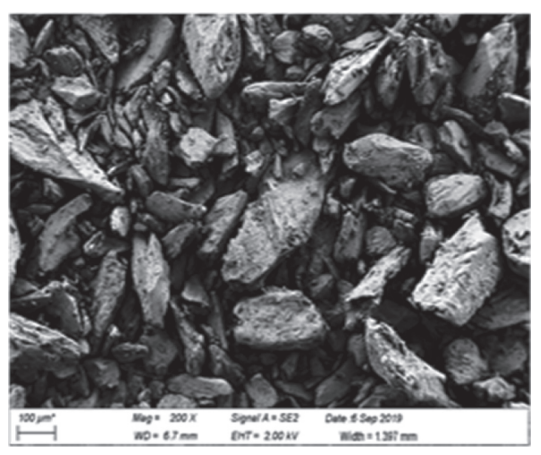

C

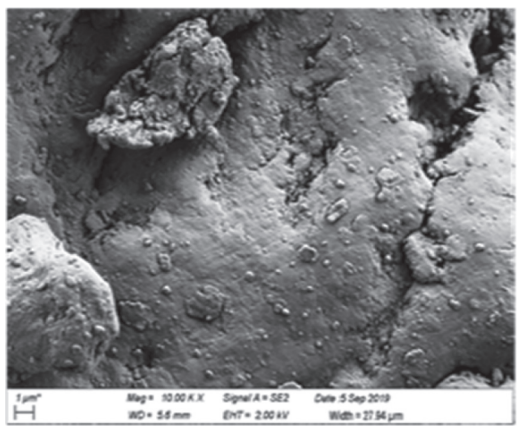

F

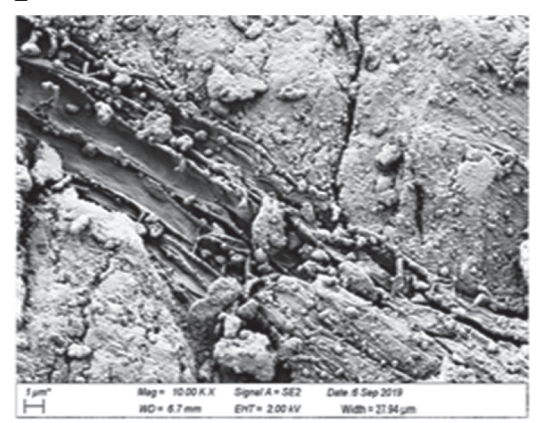

Figure 1. Microstructure of the fish powders (A, B, C, D, E) and the positive control (F) by scanning electron microscope observation (200× [a] and $10,000 \times[b])$. 
Determination of in vitro bioavailability using a cytotoxicity MTT (3-(4,5-dimethylthiazol-2-yl)-2,5-diphenyltetrazolium bromide) assay and Caco-2 (human colorectal adenocarcinoma cells) cell line model

The Caco-2 human colon cancer cell line was obtained from the American Type Cell Collection (ATCC ${ }^{\circledR}$ HTB-37 ${ }^{\mathrm{TM}}$ ). Cells were cultured in $75 \mathrm{~cm}^{2}$ tissue culture flasks (Sarstedt, SARSTEDT AG \& Co. KG, Sarstedtstraße 1, Nümbrecht, Germany) and maintained in Dulbecco's Modified Eagle Medium supplemented with $10 \%(\mathrm{v} / \mathrm{v})$ heat-inactivated fetal bovine serum and a mixture of antibiotics to give a final concentration of $50 \mu \mathrm{g} / \mathrm{mL}$ penicillin, $50 \mu \mathrm{g} / \mathrm{mL}$ streptomycin and maintained in a humidified incubator (Sanyo ${ }^{\mathrm{TM}}$, MCO20AIC, $\mathrm{CO}_{2}$ Incubator, Sanyo, Osaka, Japan) with $5 \% \mathrm{CO}_{2}$ at $37^{\circ} \mathrm{C}$. Cells were sub-cultured every 2 days or when the cells reached a confluency of $80-90 \%$ and were detached from the flasks using $0.25 \%$ trypsin-ethylene diamine tetraacetic acid solution following the procedure described by Glahn et al. (1998). All reagents and media were purchased from SigmaAldrich, Inc., St. Louis, MO, USA.

To assess cytotoxicity, samples $E$ and $F$ were selected and $\mathrm{CaCO}_{3}$ was included as the calcium positive control. The cytotoxicity was measured by MTT assay (Twentyman \& Luscombe, 1987; Hansen et al., 1989). Prior to the uptake experiment, Caco-2 cells were seeded in 96-well plates (Sarstedt, SARSTEDT AG \& Co. KG, Sarstedtstraße 1, Nümbrecht, Germany) at a concentration of $8 \times 10^{4}$ cells per well. The cells were incubated at $37^{\circ} \mathrm{C}$ in $5 \% \mathrm{CO}_{2}$ for $24 \mathrm{~h}$ to allow them to become fully differentiated. Then the medium was discarded, and digested samples in duplicates were added to the wells at different ratios $(\mathrm{v} / \mathrm{v})$ of digested samples/ medium (50/50, 25/75, 10/90, 5/95, 4/96, 3/97, 2/98 and 1/99) at $37^{\circ} \mathrm{C}$ for $2 \mathrm{~h}$. The results were based on the colorimetric data obtained using spectrophotometer (Biotek brand Synergy HT model) and represented as the $\%$ of viable cells. After the selection of the non-toxic sample concentration, cells were seeded on transpermeable polyester inserts of 12-well plates $\left(0.4 \mu \mathrm{m}\right.$ pore size and $12 \mathrm{~mm}$ diameter, Transwells ${ }^{\circledR}$ Permeable Support plates, Costar $^{\circledast}$, Costar/Corning, One Riverfront Plaza, Corning, NY, USA). The culture media were added into both apical and basolateral chambers of the transwells and the cells were incubated at $37^{\circ} \mathrm{C}$ in $5 \% \mathrm{CO}_{2}$. Then the cells were maintained for 21 days and the medium was changed every 2 days until they were fully differentiated as a monolayer. During the incubation time, the monolayer integrity was measured by transepithelial electrical resistance (TEER-Millicell-ERS, MERSStX01 electrode). When TEER values reached to $1,000 \Omega \mathrm{cm}^{2}$, the cells were assumed to be fully differentiated as a monolayer and suitable for nutrient or calcium transport studies.

After 21 days, and prior to adding the digested samples, apical and basolateral compartments were washed with phosphate buffered saline (Sigma-Aldrich, USA) to remove non-attached cells and $445 \mu \mathrm{L}$ and $1,500 \mu \mathrm{L}$ of Hank's medium (SigmaAldrich, USA) was added on the apical and basolateral compartments, respectively. Plates were incubated at $37^{\circ} \mathrm{C}$ for $30 \mathrm{~min}$ in a $5 \% \mathrm{CO}_{2}$ humidified atmosphere to reach equilibration of the monolayer. A final ratio of 10/90 of digested sample/media in triplicate, based on cytotoxicity experiments, was added in the apical compartment and transport buffer was added to the basolateral chamber. Plates were incubated for another $2 \mathrm{~h}$, after which the samples $\mathrm{E}, \mathrm{F}$ and $\mathrm{CaCO}_{3}$ from the basolateral chamber were collected for the determination of total calcium content. Measurements were conducted in triplicate samples of powders $\mathrm{E}, \mathrm{F}$ and $\mathrm{CaCO}_{3}$. The \% calcium absorption was calculated as: (calcium collected/ calcium added) * 100 . The quantification of the total calcium was carried out using the inductively coupled plasma-mass spectrometry technique from an external company (FBA Laboratories, Co. Waterford, Ireland).

\section{Statistical method}

For comparison of the particle size of the powders $E$ and $F$, and for comparison of solubility of the fish powders at different temperatures (room temperature [RT] and $50^{\circ} \mathrm{C}$ ): two-sample t-test was performed at the level of significance 0.05 . For comparison between the samples (powders A, E and F) and control (milk and $\mathrm{CaCO}_{3}$ ), in the soluble calcium concentration and total calcium absorption measurements, one-way analysis of variance single-factor analysis method was used at the level of significance 0.05 .

\section{Results}

\section{Mineral analysis}

The composition of fish powders $\mathrm{A}$ and $\mathrm{E}$ is provided in Table 1 . Regarding the calcium content, sample A contained $195 \mathrm{~g} / \mathrm{kg}$ calcium, while sample E had $290 \mathrm{~g} / \mathrm{kg}$ calcium. Therefore, the calcium level in sample $E$ was closer to that of the control powder (commercially available bone fish powder, sample F), which was $251 \mathrm{~g} / \mathrm{kg}$ (Table 1). Moreover, sample E was also comparable with powder $\mathrm{F}$ for the other minerals tested, including phosphorous, magnesium, zinc, manganese, copper and iron.

\section{Particle size and microstructure of fish powder}

All the samples provided by BII (fish powders A, B, C, D, E) exhibited smaller particle size than the commercially available bone fish powder $F$ (Table 2). Meanwhile, sample $E$ had the smallest particle size and was approximately 10 times smaller than powder $\mathrm{F}(P$-value $=0.02 \leq 0.05)$. The results confirmed that the particles of Bll powders were smaller and more uniform than powder $F$. In terms of microstructure, powder $A$ was most similar to powder $F$ (Figure 1A and B). 
Table 1: Composition of fish powders A, E and $F(g / k g)$

\begin{tabular}{lccc}
\hline $\begin{array}{l}\text { Composition } \\
\text { (g/kg) }\end{array}$ & \multicolumn{3}{c}{ Samples } \\
\cline { 2 - 4 } & $\begin{array}{c}\text { B-1 } \\
\text { (1909-B-original) }\end{array}$ & $\begin{array}{c}\text { C-25 } \\
\text { (C-3718-8) } \\
\text { E }\end{array}$ & $\begin{array}{c}\text { Positive } \\
\text { control } \\
\text { F }\end{array}$ \\
\hline Protein & 363 & 248 & 250 \\
Collagen & 90.4 & 97.6 & 142.7 \\
Calcium (Ca) & 194.7 & 290 & 251.3 \\
Phosphorous (P) & 94.7 & 132 & 127.5 \\
Magnesium (Mg) & 5.1 & 6.77 & 4.3 \\
Sulphur (S) & $\mathrm{NA}$ & 1.82 & 2.5 \\
Potassium (K) & 19.8 & $143^{1}$ & 0.3 \\
Sodium (Na) & 31.6 & 117 & $\mathrm{NA}$ \\
Zinc (Zn) & $77^{1}$ & $76.1^{1}$ & $90^{1}$ \\
Manganese (Mn) & $12.5^{1}$ & $16.1^{1}$ & $17.2^{1}$ \\
Iron (Fe) & $15^{1}$ & $6.2^{1}$ & $6.2^{1}$ \\
Selenium (Se) & $\mathrm{NA}$ & $<0.50^{1}$ & $0.69^{1}$ \\
Copper (Cu) & $0.85^{1}$ & $0.26^{1}$ & $0.158^{1}$ \\
Boron (B) & $10.6^{1}$ & $2.3^{1}$ & $<5^{1}$ \\
\hline
\end{tabular}

${ }^{1}(\mathrm{mg} / \mathrm{kg})$

\section{Physicochemical properties: solubility and rheology analysis}

All samples exhibited highest solubility at $\mathrm{pH} 3$, and only marginal differences in solubility were observed at RT compared with $50^{\circ} \mathrm{C}$ at different $\mathrm{pH}$ among all powders (Figure 2). The soluble calcium concentration correlated with total solubility, with the highest soluble calcium found at $\mathrm{pH} 3$ and lowest at $\mathrm{pH} 7$ (Table 3). At higher $\mathrm{pH}$, calcium solubility was very low in all cases. Powder $\mathrm{B}$ exhibited the highest soluble ion concentration $(158.76 \mathrm{mg} / \mathrm{L})$ at $\mathrm{pH} 3$ at RT compared to other powders A, C, D, E and F (Table 3). Consequently, smaller particle size did not correlate with higher solubility (Tables 2 and 3 ). Table 4 shows the conductivity (millisiemens/centimetre or $\mathrm{mS} / \mathrm{cm}$ ) of powder samples A-F, which increased in parallel with increasing $\mathrm{pH}$ for all powders. The $\mathrm{pH}$ of the powders in solution $(10 \% \mathrm{w} / \mathrm{v})$ in water ranged from 6.96 to 9.09 , with sample A having the lowest value and samples $\mathrm{D}$ and $\mathrm{E}$ showing the highest $\mathrm{pH}$ values, while reconstituted powder $\mathrm{F}$ had a $\mathrm{pH}$ of 7.33 in water (Table 5).

\section{Comparative in vitro gastrointestinal tract treatment for} determination of soluble ionic calcium concentration

After simulated gastric digestion, $\mathrm{CaCO}_{3}$ (positive control) showed the highest concentration of soluble ionic calcium $(24,400$ and $66,400 \mathrm{mg} / \mathrm{L})$ in both replicates, while powders A, E and $F$ showed higher values of soluble ionic calcium compared to milk powder (Figure 3). Among the samples tested, sample $E$ showed the highest soluble calcium compared to $A, F$ and milk samples with significant difference observed $(P<0.01)$.

\section{Comparative in vitro calcium absorption study using the Caco-2 cell line model}

All ratios of the digested samples added to the cell monolayer showed that the percentage of cell viability did not fall by more than $1 \%$, thus these solutions were not toxic to the cell line (Figure 4). The ratio of 10/90 (sample/buffer) was selected to carry out the calcium bioavailability experiment of the digested samples as it was the highest amount of calcium that showed no toxic effects during the preliminary experiments. The initial amount of calcium measured in samples $\mathrm{E}, \mathrm{F}$ and $\mathrm{CaCO}_{3}$ were at an average of $740 \mathrm{mg} / \mathrm{kg}, 460 \mathrm{mg} / \mathrm{kg}$ and $2,088 \mathrm{mg} / \mathrm{kg}$, respectively, before they were added to the cells.

After 21 days of incubation, the TEER values were over $1,000 \Omega \mathrm{cm}^{2}$, indicating that the monolayer was intact and healthy and confirmed the integrity of the cell membrane for calciumabsorption experiments. Inall cases, the cell monolayer maintained the integrity (TEER values $>1,000 \Omega \mathrm{cm}$ ) after treatment (Figure 5). Treatment with sample $\mathrm{E}$ resulted in the highest average absorption $(28.15 \%)$, while sample $\mathrm{F}$ and $\mathrm{CaCO} 3$ showed 22.71 and $6.7 \%$ solubility, respectively (Figure 6A). Therefore, fish powder $\mathrm{E}$ presented higher $\mathrm{Ca}$ absorption in comparison with commercial fish powder $F$. The total calcium from powders $E$ and $F$ absorbed was $197.3 \pm$ 3.5 and $101.5 \pm 21.1 \mathrm{mg} / \mathrm{kg}$, respectively, meanwhile the total calcium from $\mathrm{CaCO}_{3}$ was $140.64 \pm 43.66 \mathrm{mg} / \mathrm{kg}$. Treatment with fish powder $\mathrm{E}$ resulted in significantly higher $(P<0.05)$ calcium absorption compared with sample $F$ (Figure 6B).

Table 2: Particle size of the powders analysed using Mastersizer 3,000 ( \pm SD)

\begin{tabular}{lcccccc}
\hline Code & Sample ID & Dx $(\mathbf{9 0} \boldsymbol{\mu m})$ & Dx $(\mathbf{5 0} \boldsymbol{\mu m})$ & Dx $(\mathbf{1 0} \boldsymbol{\mu m})$ & $\mathbf{D}[\mathbf{4 , 3}](\boldsymbol{\mu m})$ & $\mathbf{D}[\mathbf{3 , 2}](\boldsymbol{\mu m})$ \\
\hline B-1 & A & $182( \pm 1.41)$ & $69.05( \pm 0.92)$ & $23.25( \pm 1.06)$ & $89.95( \pm 1.06)$ & $46.4( \pm 1.41)$ \\
B-2 & B & $106.5( \pm 0.71)$ & $50.6( \pm 0.42)$ & $18.7( \pm 0.28)$ & $57.7( \pm 0.57)$ & $36.2( \pm 0.42)$ \\
C-60 & C & $84.35( \pm 0.07)$ & $32.7( \pm 0.14)$ & $10.03( \pm 0.10)$ & $43.6( \pm 0.00)$ & $19.05( \pm 0.21)$ \\
C-33 & D & $31.85( \pm 0.21)$ & $14.9( \pm 0.14)$ & $4.15( \pm 0.07)$ & $16.75( \pm 0.07)$ & $6.725( \pm 0.06)$ \\
C-25 & E & $26.6( \pm 0.00)$ & $12.65( \pm 0.07)$ & $3.68( \pm 0.04)$ & $14.15( \pm 0.07)$ & $6.03( \pm 0.04)$ \\
Control (positive) & F & $293( \pm 2.83)$ & $140.5( \pm 3.54)$ & $45.2( \pm 1.41)$ & $157( \pm 2.83)$ & $78.1( \pm 1.70)$ \\
\hline
\end{tabular}


a)

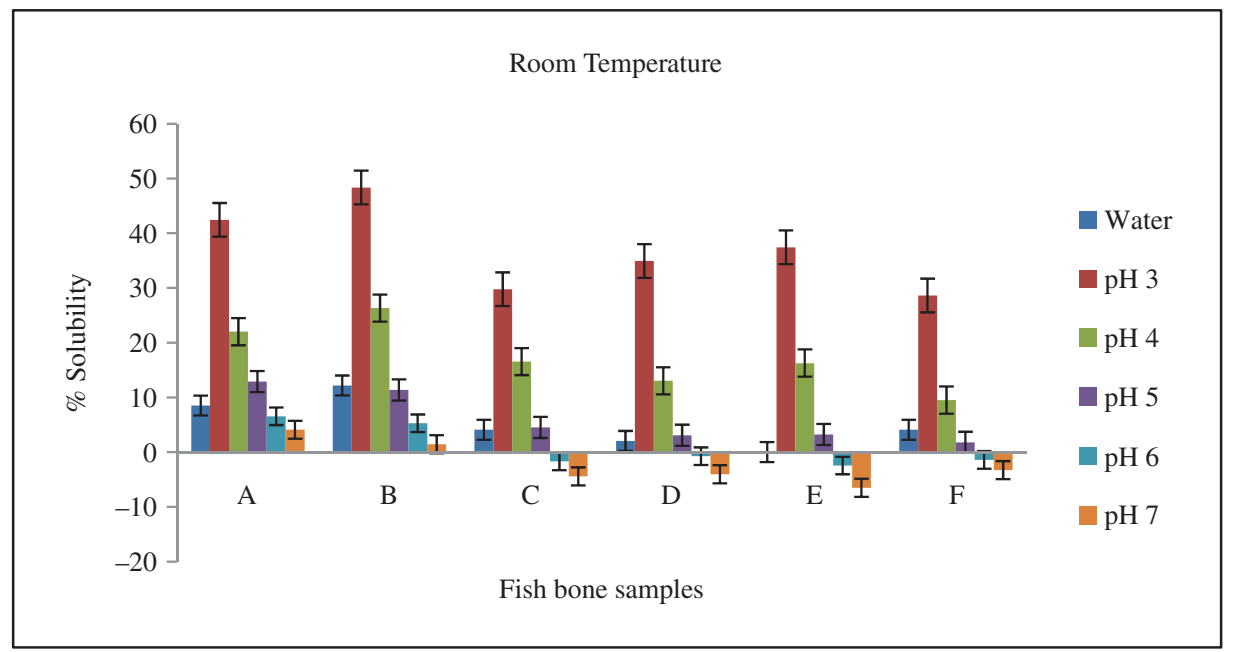

b)

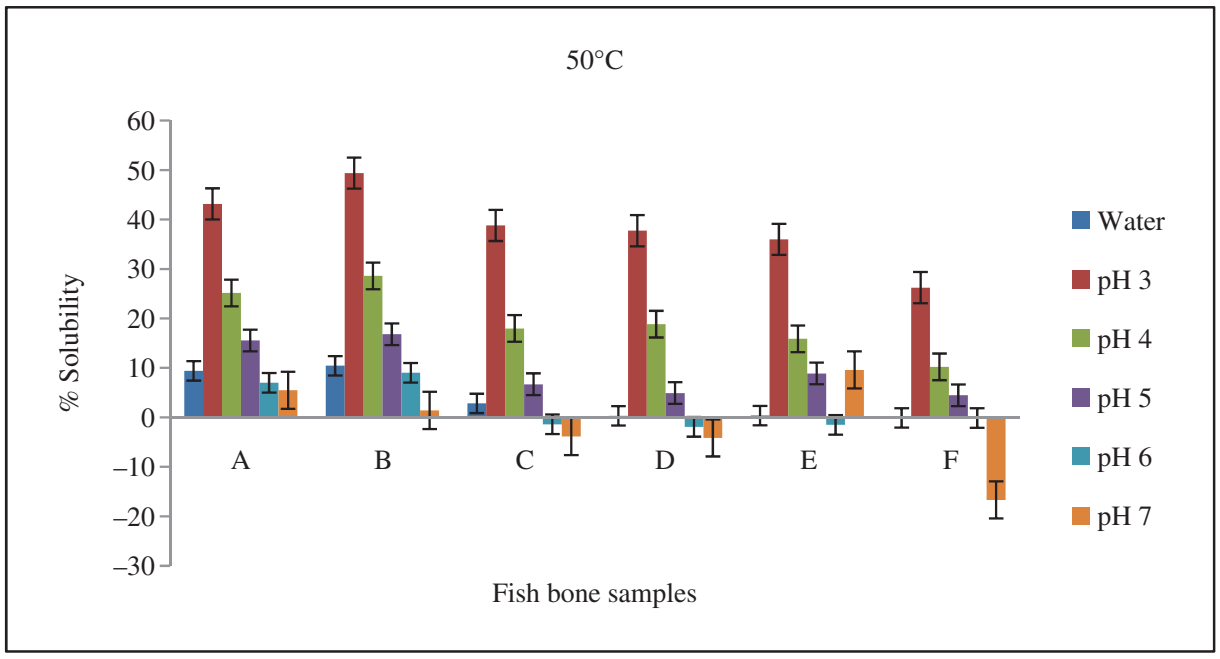

Figure 2. Solubility of the fish powders (A, B, C, D, E and F) at room temperature (a) and $50^{\circ} \mathrm{C}(\mathrm{b})$ at different $\mathrm{pH}$ values. Data were presented as mean \pm standard deviation.

Table 3: Soluble calcium ion concentration $(\mathrm{mg} / \mathrm{L})$ of fish powders at different $\mathrm{pH}$ tested at room temperature $(\mathrm{RT})$ and $50^{\circ} \mathrm{C}$

\begin{tabular}{|c|c|c|c|c|c|c|c|c|c|c|c|c|}
\hline \multirow{3}{*}{$\begin{array}{l}\text { Powders } \\
\mathrm{pH} \text { tested }\end{array}$} & \multicolumn{12}{|c|}{ Calcium (mg/L) } \\
\hline & \multicolumn{2}{|c|}{ A } & \multicolumn{2}{|c|}{ B } & \multicolumn{2}{|c|}{ C } & \multicolumn{2}{|c|}{ D } & \multicolumn{2}{|c|}{ E } & \multicolumn{2}{|c|}{ F (Positive control) } \\
\hline & RT & $50^{\circ} \mathrm{C}$ & RT & $50^{\circ} \mathrm{C}$ & RT & $50^{\circ} \mathrm{C}$ & RT & $50^{\circ} \mathrm{C}$ & RT & $50^{\circ} \mathrm{C}$ & RT & $50^{\circ} \mathrm{C}$ \\
\hline Water & 34.802 & 18.649 & 38.042 & 20.06 & 6.687 & 6.133 & 3.228 & 3.622 & 2.689 & 3.709 & 41.414 & 20.905 \\
\hline $\mathrm{pH} 3$ & 139.699 & 101.323 & 158.762 & 108.203 & 140.281 & 111.176 & 127.395 & 112.185 & 120.99 & 114.889 & 135.134 & 103.85 \\
\hline $\mathrm{pH} 4$ & 42.092 & 31.626 & 53.334 & 33.107 & 54.679 & 30.871 & 50.913 & 30.902 & 55.616 & 30.578 & 54.37 & 29.743 \\
\hline pH 5 & 9.966 & 10.343 & 11.013 & 10.416 & 9.947 & 8.975 & 9.557 & 9.134 & 10.448 & 9.376 & 9.309 & 8.979 \\
\hline $\mathrm{pH} 6$ & 4.596 & 4.315 & 4.868 & 4.467 & 4.412 & 3.82 & 4.44 & 3.906 & 4.518 & 4.048 & 3.83 & 3.502 \\
\hline $\mathrm{pH} 7$ & 2.166 & 2.014 & 2.237 & 1.99 & 1.758 & 1.543 & 1.89 & 1.638 & 1.982 & 1.676 & 1.644 & 1.507 \\
\hline
\end{tabular}


Table 4: Conductivity $(\mathrm{mS} / \mathrm{cm})$ of fish powder samples at different $\mathrm{pH}$

\begin{tabular}{lcccccc}
\hline $\begin{array}{l}\text { Conductivity } \\
\text { (mS/cm) }\end{array}$ & A & B & C & D & E & F \\
\hline Water & $708^{1}$ & $694^{1}$ & $374^{1}$ & $405^{1}$ & $407^{1}$ & $90.7^{1}$ \\
$\mathrm{pH} \mathrm{3}$ & 8.12 & 8.16 & 7.88 & 8.05 & 8.15 & 7.74 \\
$\mathrm{pH} 4$ & 9.83 & 9.88 & 9.59 & 9.75 & 9.76 & 9.46 \\
$\mathrm{pH} \mathrm{5}$ & 11.67 & 11.78 & 11.61 & 11.58 & 11.5 & 11.52 \\
$\mathrm{pH} \mathrm{6}$ & 13.72 & 13.65 & 13.54 & 13.67 & 13.69 & 13.41 \\
$\mathrm{pH} 7$ & 17.48 & 17.41 & 17.22 & 17.33 & 17.2 & 17.16 \\
\hline
\end{tabular}

${ }^{1}$ (microsiemens/centimetre or $\mu \mathrm{S} / \mathrm{cm}$ ).

Note: Single sample tested for each powder for conductivity.

Table 5: $\mathrm{pH}$ of the powders in water $(10 \% \mathrm{w} / \mathrm{v})$

\begin{tabular}{lc}
\hline Powders & pH measured \\
\hline A & $6.96( \pm 0.01)$ \\
B & $6.97( \pm 0.33)$ \\
C & $8.97( \pm 0.93)$ \\
D & $9.13( \pm 1.11)$ \\
E & $9.09( \pm 1.02)$ \\
F & $7.33( \pm 0.51)$ \\
\hline
\end{tabular}

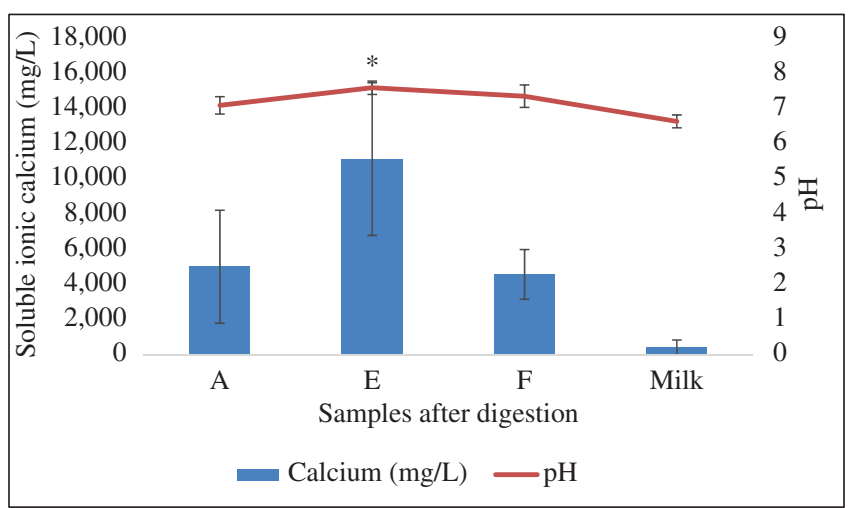

Figure 3. Soluble ionic calcium concentration (mg/L) and $\mathrm{pH}$ of samples A, E, F and milk (control), after simulated gastric digestion protocol. Among the samples tested, there was a significance difference observed with $P<0.01$.

\section{Discussion}

Powder E, the most processed of the samples analysed, proved comparable to powder $\mathrm{F}$ in terms of mineral content, especially with regard to calcium and phosphorous. The

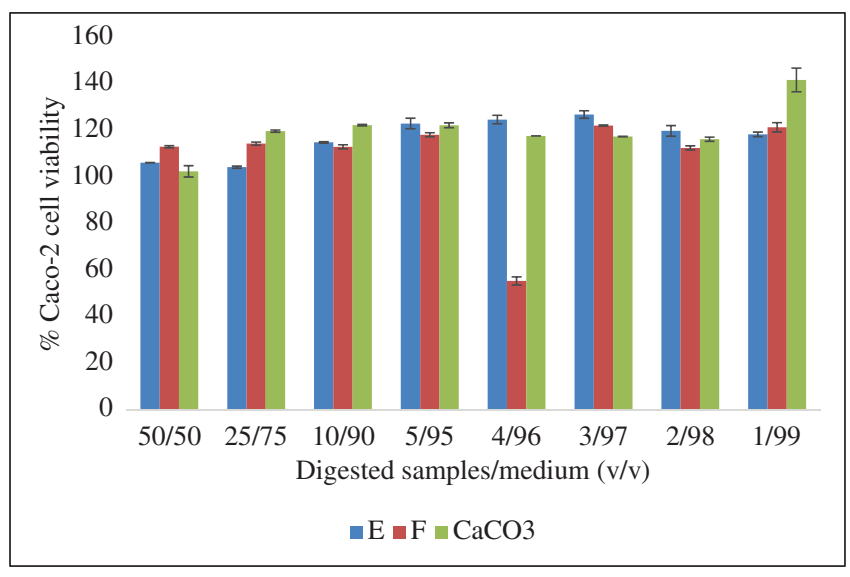

Figure 4. Cell viability (\%) Caco-2 cells in the presence of powders $\mathrm{E}, \mathrm{F}$ and $\mathrm{CaCO}_{3}$ at different ratios $(\mathrm{v} / \mathrm{v})$ of digested samples/medium using the cytotoxicity test (MTT). Powders $E$ and $F$ were selected to assess cytotoxicity by MTT assay at different ratios (v/v) of digested samples/medium (50/50, 25/75, 10/90, 5/95, 4/96, 3/97, 2/98 and 1/99), and $\mathrm{CaCO}_{3}$ was included as the positive control.

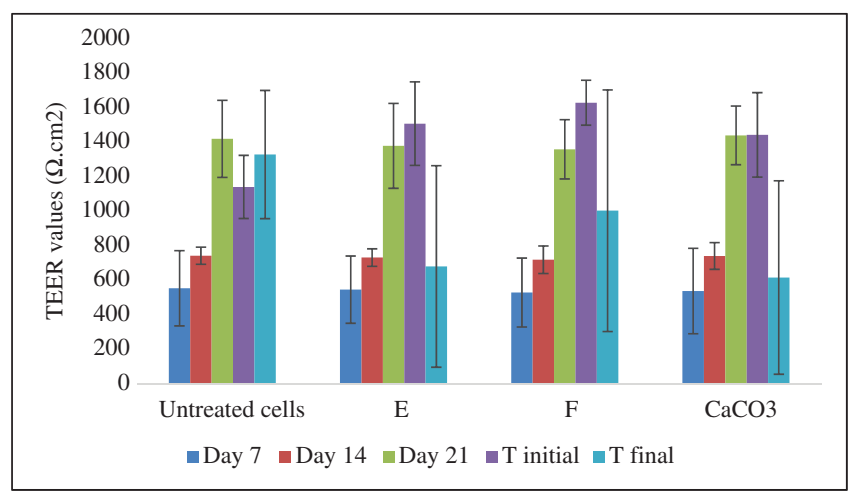

Figure 5. Transepithelial/transendothelial electrical resistance (TEER) values $\left(\Omega \mathrm{cm}^{2}\right)$ during differentiation of the Caco- 2 cells with powders $\mathrm{E}, \mathrm{F}, \mathrm{CaCO}_{3}$ and untreated cells after 7, 14 and 21 days of incubation (Day 21) until they were fully differentiated as a monolayer. A final ratio of $10 / 90$ of digested sample/media in triplicates was added in the apical compartment as treatment and the TEER values at Time $0 \mathrm{~h}$ ( $\mathrm{T}$ initial) and after $2 \mathrm{~h}$ ( $\mathrm{T}$ final) of incubation were calculated. Reduction in TEER values before (T0) and after (T2) treatment was observed in all Caco-2 cells with treated samples, but sample $F$ showed less toxicity to the cells compared to sample $\mathrm{E}$ and $\mathrm{CaCo}_{3}$.

crude powder $\mathrm{A}$ had a higher protein content than powder $\mathrm{F}$ but similar to levels reported for salmon $(350 \mathrm{~g} / \mathrm{kg}$ ) and cod (324 g/kg) bone powders (Malde et al., 2010a). The mineral composition analysis hence revealed that the Bll fish bone powders A (crude) or E (highly processed) are potential sources of important minerals for human nutrition. 

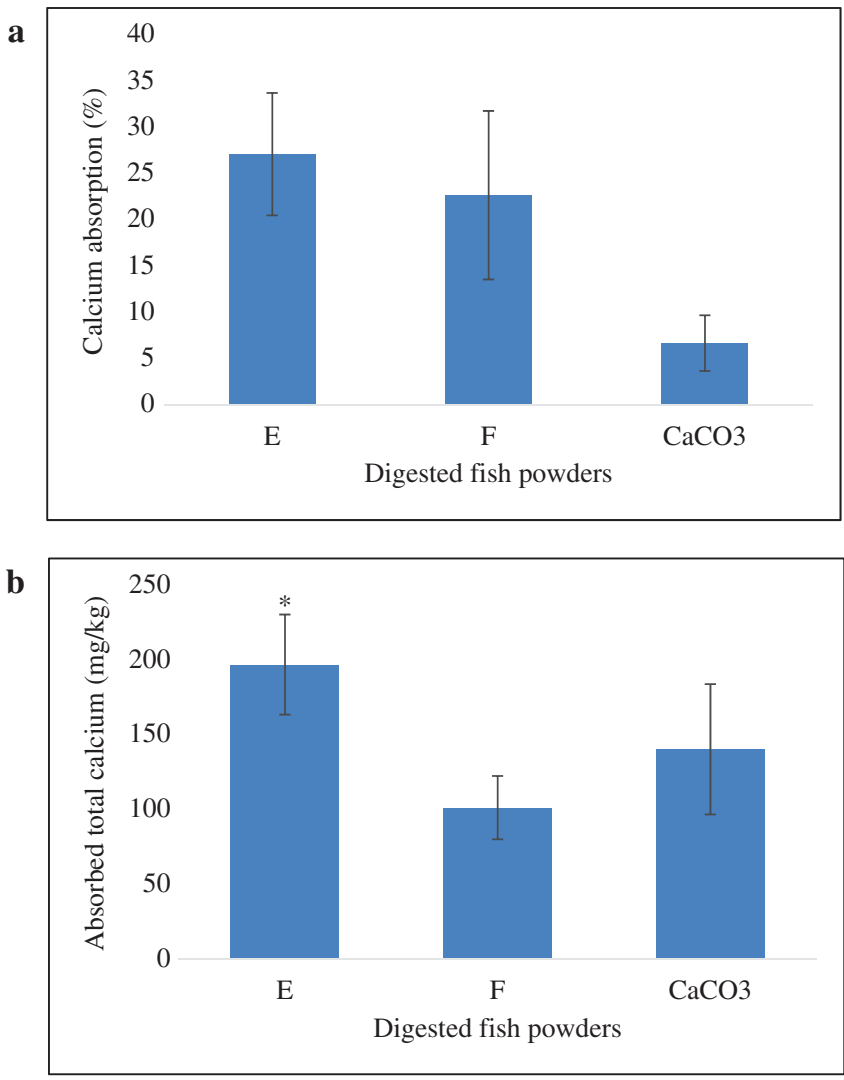

Figure 6. In vitro calcium absorption study using Caco-2 cell line model. (a) Calcium absorption (\%) and (b) total calcium absorbed $(\mathrm{mg} / \mathrm{kg})$ of powders $\mathrm{E}, \mathrm{F}$ and $\mathrm{CaCO}_{3}$. There was a significance difference observed among samples with total calcium absorbed with $P<0.05$. Data are presented as mean \pm standard deviation.

Fish bone is composed of approximately $30 \%$ collagen and 60-70\% inorganic compounds such as calcium, phosphorus, magnesium, iodine and selenium (Välimaa et al., 2019). Fish bone naturally contains calcium and phosphorus in the right ratio of approximately 2:1 to form hydroxyapatite, which is considered the most bioavailable form of calcium (Venkatesan et al., 2015; Välimaa et al., 2019). A similar calcium (194.7, 290, $251.3 \mathrm{~g} / \mathrm{kg}$ ) and phosphorus (94.7, 132 and $127.5 \mathrm{~g} /$ $\mathrm{kg}$ ) ratio of 2:1 was identified in the fish bone powders $A$, $\mathrm{E}$ and $\mathrm{F}$ analysed. In addition to calcium, phosphorus used by the fertiliser and chemical industries can be isolated and recovered from fish bones (Välimaa et al., 2019).

Solubility of the fish powders was investigated as solubilisation determines the release of nutrients in the powder. The solubility was inversely associated with $\mathrm{pH}$, with all powders exhibiting not more than $10 \%$ solubility at $\mathrm{pH} 7$ and approximately $40 \%$ solubility at $\mathrm{pH} 3$. However, temperature did not play a significant role in the solubility profile of fish powders. Marginal differences were found at RT compared with $50^{\circ} \mathrm{C}$. Calcium solubility was very low in all cases, which followed a similar trend to total solubility at $\mathrm{pH}$ 7 , whereas that with the highest soluble calcium was found at $\mathrm{pH}$ 3. Therefore, the soluble nature of fish powder positively correlates with calcium release from the powder. Meanwhile, it was noted that as $\mathrm{pH}$ increased, the conductivity and calcium activity decreased among all powders tested. In addition, it was noted that particle size of powders was not a critical factor for solubilisation of the fish powders. Although with 10 times smaller particle size than powder F, powder E did not show higher soluble calcium compared to powder $\mathrm{F}$ at $\mathrm{RT}$ or $50^{\circ} \mathrm{C}$. The solubility of calcium in the gastrointestinal tract is important before it can be absorbed, but certain dietary factors can impact calcium solubility, thereby affecting calcium bioavailability at the absorptive surface of intestinal cells. In vitro bioaccessibility/bioavailability methods are useful to provide knowledge on either micronutrient absorbability (a component of bioavailability) or on the potential for a nutrient to be absorbed, that is, bioaccessibility (Etcheverry et al., 2012; Mackie et al., 2020). The principal in vitro methods for measuring bioaccessibility and/or bioavailability includes the gastrointestinal model (e.g. INFOGEST static Egger et al., 2016; Brodkorb et al., 2019; Minekus, 2015) for bioaccessibility and the Caco-2 models for bioavailability. There are several types of in vitro digestion methods that are commonly used to study the bioaccessibility of food ingredients, which can be divided into static and dynamic methods. These models aim to simulate the physiological conditions of the upper gastrointestinal tract, namely the oral, gastric and small intestinal phases. Recently, an international consensus of the digestion conditions was reached within the European COST Action INFOGEST (http://www.cost-infogest.eu/) (Minekus et al., 2014; Brodkorb et al., 2019).

The calcium solubility level, obtained by applying the in vitro digestion method, makes it possible to establish trends in the bioavailability of calcium. Fish bone powders $A, E$ and $F$ were compared to milk powder and $\mathrm{CaCO}_{3}$ (as positive controls) for in vitro bioaccessibility using simulated gastrointestinal tract treatment. Milk and calcium carbonate are used as the standard reference calcium sources for digestibility. Following simulated oral, gastric and duodenal in vitro digestion processes, fish powders $A, E$ and $F$ showed higher values of soluble ionic calcium than milk powder. Also, both powders $A$ and $E$ showed higher soluble calcium ( $\mathrm{mg} / \mathrm{L}$ ) than powder F. Similarly, a study conducted by Yin et al. (2016) reported that the calcium solubility of ultrafine fish bone powder (UFBP) significantly increased as the particle size decreased, which might be due to the increase of specific surface area and the destruction of the collagen matrix. It was also suggested that a decrease of fish bone particle size could facilitate the absorption of calcium (Yin et al., 2016). Comparatively, our finding indicated that blue whiting fish bone powders (A and 
E) not only have smaller particle size, similar soluble calcium ion concentration but also higher bio-accessible calcium compared with the commercial fish powder $F$.

In vitro bioavailability of calcium in the commercial powder F was previously reported (Beldman et al., 1996; https:// nutrizing.co.nz/product/calcium-fish-bone-powder/) using mouse osteoblast cell lines. The results identified that powder $\mathrm{F}$ matched $\mathrm{CaCO}_{3}$ in bioavailability. They also identified a small but significant effect of powder $F$ on osteoblast mineralisation assisting bone-making osteoblast cells to produce bone mineral. This indicates positive effect of powder $F$ on bone cell function.

Previous studies demonstrated that calcium from commercial fish like salmon and cod is absorbed as efficiently as $\mathrm{CaCO}_{3}$ in both growing pigs and humans (Malde et al., 2010a and 2010b). Malde et al. (2010a) demonstrated calcium absorption rates of $21.9 \%$ and $22.5 \%$ for cod and salmon bones, respectively, and $27.4 \%$ for $\mathrm{CaCO}_{3}$ in humans. In our study using the Caco-2 cell line, powder E showed the highest absorption (28.15\%), compared to powder $\mathrm{F}(22.71 \%)$ and $\mathrm{CaCO} 3(6.7 \%)$. The TEER assay also confirmed that powder $\mathrm{E}$ presented higher $\%$ and total calcium absorption compared with powder $\mathrm{F}$ and $\mathrm{CaCO}_{3}$. Moreover, the results demonstrated that the composition of blue whiting fish bone powder $\mathrm{E}$ is extremely bioavailable and did not exhibit a cytotoxic effect on the Caco-2 cell line. Therefore, we can speculate that the difference in mineral composition, particle size and bioavailability might have influenced the difference in absorption of calcium between powders $E$ and F. A study by Suntornsaratoon et al. (2018) demonstrated that lactating rats given either tuna bone or purified $\mathrm{CaCO}_{3}$ produced milk with higher calcium concentration, which, in turn, increased bone mineral density in the offspring. Therefore, the blue whiting fish bone powder $\mathrm{E}$ with comparable calcium absorption ratios to other fish bone powders from cod and salmon (Malde et al., 2010a) can also be utilised as an alternative calcium source to test for bioavailability and absorption in future animal and human studies.

Overall, our data indicate the potential of Bll fish powder $E$ as a source of highly bio-accessible and bioavailable calcium. The calcium-rich blue whiting fish bone powder E compares well with existing calcium sources, in terms of physicochemical properties, bioaccessibility and bioavailability, based on in vitro assay and cell culture studies. Thus, blue whiting fish bone powder has the potential to be an alternative source of calcium especially in promoting bone formation and as a value-added product that can be used in a wide range of industrial applications. Future preclinical and human studies will be required to confirm the potential of fish powder E as a calcium-rich nutritional supplement for human health. In this regard, the blue whiting fishery represents a significant opportunity for the Irish seafood sector and related industries due to its relatively large quota and global availability.

\section{Acknowledgements}

This project was funded by BIM and DAFM via the Seafood Processing Innovation scheme via the Seafood R\&D Programme from the Irish Government and European Maritime and Fisheries Fund 2014-2020.

\section{References}

Ben-Othman, S., Joudu, I. and Bhat, R. 2020. Bioactives from agrifood wastes: present insights and future challenges. Molecules 25: 510 .

Beldman, G., Osuga, D., Whitaker, J.R. 1996. Some characteristics of $\beta$-D-Xylopyranosidases, $\alpha$-L-arabinofuranosidases and an arabinoxylan $\alpha$-L-arabinofuranohydrolase from wheat Bran and germinated wheat. Journal of Cereal Science 23: 169-180.

Brennan, O., Sweeney, J., O'meara, B., Widaa, A., Bonnier, F., Byrne, H.J., O'Gorman, D.M. and O'Brien, F.J. 2017. A natural, calcium-rich marine multi-mineral complex preserves bone structure, composition and strength in an ovariectomised rat model of osteoporosis. Calcified Tissue International 101: 445-455.

Brodkorb, A., Egger, L., Alminger, M., Alvito, P., Assunção, R., Ballance, S., Bohn, T., Bourlieu-Lacanal, C., Boutrou, R., Carrière, F. and Clemente, A. 2019. INFOGEST static in vitro simulation of gastrointestinal food digestion. Nature Protocols 14: 991-1014.

Egger, L., Ménard, O., Delgado-Andrade, C., Alvito, P., Assunção, R., Balance, S., Barberá, R., Brodkorb, A., Cattenoz, T., Clemente, A., Comi, I., Dupont, D., Garcia-Llatas, G., Lagarda, M.J., Le Feunteun, S., Janssenduijghuijsen, L., Karakaya, S., Lesmes, U., Mackie, A.R., Martins, C., Meynier, A., Miralles, B., Murray, B.S., Pihlanto, A., Picariello, G., Santos, C.N., Simsek, S., Recio, I., Rigby, N., Rioux, L.-E., Stoffers, H., Tavares, A., Tavares, L., Turgeon, S., Ulleberg, E.K., Vegarud, G.E., Vergères, G. and Portmann, R. 2016. The harmonized INFOGEST in vitro digestion method: From knowledge to action. Food Research International 88: 217-225.

Etcheverry, P., Grusak, M.A. and Fleige, L.E. 2012. Application of in vitro bioaccessibility and bioavailability methods for calcium, carotenoids, folate, iron, magnesium, polyphenols, zinc, and vitamins B6, B12, D, and E. Frontiers in Physiology 3: 317.

FAO. 2020. The State of World Fisheries and Aquaculture 2020 Sustainability in action. Rome.

Fernández, A., Grienke, U., Soler-Vila, A., Guihéneuf, F., Stengel, D.B. and Tasdemir, D. 2015. Seasonal and geographical variations in the biochemical composition of the blue mussel (Mytilus edulis L.) from Ireland. Food Chemistry 177: 43-52. 
Flammini, L., Martuzzi, F., Vivo, V., Ghirri, A., Salomi, E., Bignetti, E. and Barocelli, E. 2016. Hake fish bone as a calcium source for efficient bone mineralization. International Journal of Food Sciences and Nutrition 67: 265-273.

Geirsdottir, M., Sigurgisladottir, S., Hamaguchi, P.Y., Thorkelsson, G., Johannsson, R., Kristinsson, H.G. and Kristjansson, M.M. 2011. Enzymatic hydrolysis of blue whiting (Micromesistius poutassou); functional and bioactive properties. Journal of Food Science $\mathbf{7 6}$ : C14-C20.

Ghosh, P.R., Fawcett, D., Sharma, S.B. and Poinern, G.E. 2016. Progress towards sustainable utilisation and management of food wastes in the global economy. International Journal of Food Science 1: 1-22.

Glahn, R.P., Lee, O.A., Yeung, A., Goldman, M.I. and Miller, D.D. 1998. Caco-2 cell ferritin formation predicts nonradiolabeled food iron availability in an in vitro digestion/Caco-2 cell culture model. Journal of Nutrition 128: 1555-1561.

Gosling, E., Doherty, S. and Howley, N. 2008. Genetic characterization of hybrid mussel (Mytilus) populations on Irish coasts. Journal of The Marine Biological Association, UK 88: 341-346.

Hansen, M.B., Nielsen, S.E. and Berg, K. 1989. Re-examination and further development of a precise and rapid dye method for measuring cell growth/cell kill. Journal of Immunological Methods 119: 203-210.

Heo, S.Y., Ko, S.C., Nam, S.Y., Oh, J., Kim, Y.M., Kim, J.I., Kim, N., Yi, M. and Jung, W.K. 2018. Fish bone peptide promotes osteogenic differentiation of MC3T3-E1 pre-osteoblasts through upregulation of MAPKs and Smad pathways activated BMP-2 receptor. Cell Biochemistry and Function 36: 137-146.

Jung, W.K. and Kim, S.K. 2007. Calcium-binding peptide derived from pepsinolytic hydrolysates of hoki (Johnius belengerii) frame. European Food Research and Technology 224: 763-767.

Karayannakidis, P.D. and Zotos, A. 2016. Fish processing by-products as a potential source of gelatin: a review. Journal of Aquatic Food Product Technology 25: 65-92.

Mackie, A., Mulet-Cabero, A.I. and Torcello-Gómez, A. 2020. Simulating human digestion: developing our knowledge to create healthier and more sustainable foods. Food \& Function 11: 9397-9431.

Malde, M.K., Bugel, S., Kristensen, M., Malde, K., Graff, I.E. and Pedersen, J.I. 2010a. Calcium from salmon and cod bone is well absorbed in young healthy men: a double-blinded randomised crossover design. Nutrition \& Metabolism 7: 61.

Malde, M.K., Graff, I.E., Siljander-Rasi, H., Venalainen, E., Julshamn, K., Pedersen, J.I. and Valaja, J. 2010b. Fish bones--a highly available calcium source for growing pigs. Journal of Animal Physiology and Animal Nutrition 94: e66-e76.

Minekus, M., Alminger, M., Alvito, P., Ballance, S., Bohn, T., Bourlieu, C., Carrière, F., Boutrou, R., Corredig, M., Dupont, D., Dufour, C., Egger, L., Golding, M., Karakaya, S., Kirkhus, B., Le Feunteun, S., Lesmes, U., Macierzanka, A., Mackie, A., Marze, S., McClements, D.J., Ménard, O., Recio, I., Santos, C.N., Singh, R.P., Vegarud, G.E., Wickham, M.S.J., Weitschies, W. and
Brodkorb, A. 2014. A standardised static in vitro digestion method suitable for food - an international consensus. Food \& Function $\mathbf{5}$ : 1113-1124.

Minekus, M., 2015. The TNO gastro-intestinal model (TIM). In: "The Impact of Food Bioactives on Health", (eds. K. Verhoeckx et al.) Springer, Cham, pages 37-46.

Nguyen, T.T., Heimann, K. and Zhang, W. 2020. Protein recovery from underutilised marine bioresources for product development with nutraceutical and pharmaceutical bioactivities. Marine Drugs 18 : 391.

Peng, Z., Hou, H., Zhang, K. and Li, B. 2017. Effect of calcium-binding peptide from Pacific cod (Gadus macrocephalus) bone on calcium bioavailability in rats. Food Chemistry 221: 373-378.

Ross, A.C., Manson, J.E., Abrams, S.A., Aloia, J.F., Brannon, P.M., Clinton, S.K., Durazo-Arvizu, R.A., Gallagher, J.C., Gallo, R.L., Jones, G., Kovacs, C.S., Mayne, S.T., Rosen, C.J. and Shapses, S.A. 2011. The 2011 report on dietary reference intakes for calcium and vitamin $D$ from the institute of medicine: what clinicians need to know. The Journal of Clinical Endocrinology \& Metabolism 96: 53-58.

Rustad, T., Storrø, I. and Slizyte, R. 2011. Possibilities for the utilisation of marine by-products. International Journal of Food Science \& Technology 46: 2001-2014.

Shahidi, F., Varatharajan, V., Peng, H. and Senadheera, R. 2019. Utilization of marine by-products for the recovery of value-added products. Journal of Food Bioactives 6.

Suntornsaratoon, P., Charoenphandhu, N. and Krishnamra, N. 2018. Fortified tuna bone powder supplementation increases bone mineral density of lactating rats and their offspring. Journal of the Science of Food and Agriculture 98: 2027-2034.

Terzioglu, P., Ogut, H. and Kalemtas, A. 2018. Natural calcium phosphates from fish bones and their potential biomedical applications. Materials Science and Engineering C 91: 899-911.

Torres-León, C., Ramírez-Guzman, N., Londoño-Hernandez, L., Martinez-Medina, G.A., Díaz-Herrera, R., Navarro-Macias, V., Alvarez-Pérez, O.B., Picazo, B., Villarreal-Vázquez, M., AscacioValdes, J. and Aguilar, C.N. 2018. Food waste and byproducts: an opportunity to minimize malnutrition and hunger in developing countries. Frontiers in Sustainable Food Systems 2: 52.

Twentyman, P. and Luscombe, M. 1987. A study of some variables in a tetrazolium dye (MTT) based assay for cell growth and chemosensitivity. British Journal of Cancer 56: 279-285.

Välimaa, A.-L., Mäkinen, S., Mattila, P., Marnila, P., Pihlanto, A., Mäki, M. and Hiidenhovi, J. 2019. Fish and fish side streams are valuable sources of high-value components. Food Quality and Safety 3: 209-226.

Venkatesan, J., Lowe, B., Manivasagan, P., Kang, K.-H., Chalisserry, E., Anil, S., Kim, D. and Kim, S.-K. 2015. Isolation and characterization of nano-hydroxyapatite from salmon fish bone. Materials 8: 5426-5439.

Wawrzyniak, N. and Suliburska, J. 2021. Nutritional and health factors affecting the bioavailability of calcium: a narrative review. Nutrition Reviews 79: 1307-1320. 
Yin, T., Du, H., Zhang, J. and Xiong, S. 2016. Preparation and characterization of ultrafine fish bone powder. Journal of Aquatic Food Product Technology 25: 1045-1055.

Zhang, K., Li, B., Chen, Q., Zhang, Z., Zhao, X. and Hou, H. 2018. Functional calcium binding peptides from pacific cod (Gadus macrocephalus) bone: calcium bioavailability enhancing activity and anti-osteoporosis effects in the ovariectomy-induced osteoporosis rat model. Nutrients 10: 1325. 